\title{
CONVECTIVE HEAT TRANSFER FROM HUMAN BODY (PART 2. EFFECT OF FABRIC ON HEAT TRANSFER)
}

\author{
By Yoshinobu Kamata, Toyofumi Kato, Asahito Ito* and Noboru Yahata \\ (Faculty of Technology, Tokyo University of Agriculture and Technology, \\ Nakamachi, Koganei, Tokyo 184, Japan)
}

\begin{abstract}
Convective heat transfer from the outer surface of a cylindrical heat source covered with a fabric was experimentally studied and the effect of fabrics on the transfer coefficient was examined analytically based on the results. It was found that, for fabrics less permeable to air, such as tweed or denim, the experimental and analytical methods used in this study were available; that the heat transfer coefficient was reduced by covering; and that the problem of heat transfer may be treated as if fabrics had smooth surfaces by supposing a hypothetical rest layer of air on the surface. It was also found that, for permeable fabrics as knitted fabrics, the apparent heat transfer was larger than that for less permeable ones, so that the analytical method must be improved.
\end{abstract}

\section{Introduction}

In our previous paper ${ }^{1)}$, we proposed an empirical formula by which the convective heat transfer coefficient of a human body can be estimated as a function of the air flow velocity, the diameter of the body, and the temperature difference between the body and the surrounding air.

In this paper, we studied the effect of a fabric on the heat transfer from its outer surface for forced convection, comparing the heat transfers from a clothed cylinder and from a naked cylinder.

Very few studies on the heat transfer from a clothed cylinder have been reported. Takeuchi et al. investigated experimentally and theoretically the effect of contacting condition of a cylinder and a fabric on wind penetration ${ }^{2)}$, and made it clear that the characteristics of heat transfer near the stagnation point of the cylinder can be represented by the fundamental physical properties of the air flow and fabrics, and by the contact coefficient ${ }^{3)}$.

\footnotetext{
* Present address: Patent Office of Ministry of International Trade and Industry, Kasumigaseki, Chiyoda-ku, Tokyo 100, Japan.
}

\section{Experiments}

We applied the same experimental apparatus and method as in our previous work ${ }^{1)}$, which are briefly reviewed here.

\subsection{Experimental apparatus and procedure}

A cylinder which was electrically heated, had constant surface temperature, and was covered with a fabric (Fig. 1), was set in an open-circuit wind tunnel. Copper-constantan thermocouples of $0.1 \mathrm{~mm}$ in diameter were set at intervals of 20 degrees in the fabric specimen, and the circumferential temperature distributions were measured

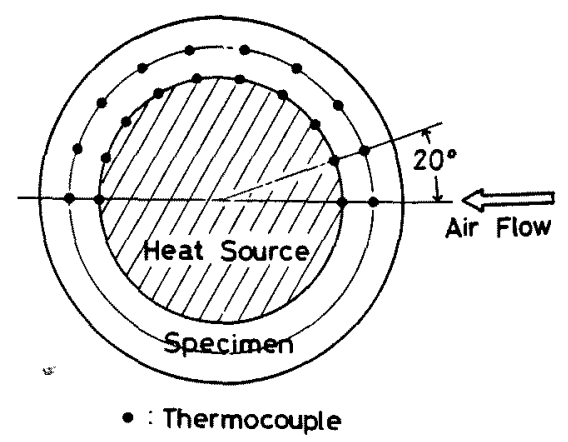

Fig. 1 Schematic cross section of the test cylinder covered with a cloth, and the setting points of thermocouples. 
by rotating the cylinder at an angle of 5 degrees. Considering the symmetry of the flow, a half part of the circumference was used for measurement. The experiment was done in a room maintained at $20 \pm 0.5^{\circ} \mathrm{C}$ and $65 \pm 5 \% \mathrm{RH}$.

The thickness of each specimen was measured as shown in Fig. 2. The diameter of the cylinder including the covered fabric was determined from the distance $D$ defined in Fig. 2; $D$ was measured with a reading microscope under the thread tension of $1 \mathrm{gf}$. The thickness of the specimen $s$ was calculated from $D$ and the diameter of the naked cylinder.

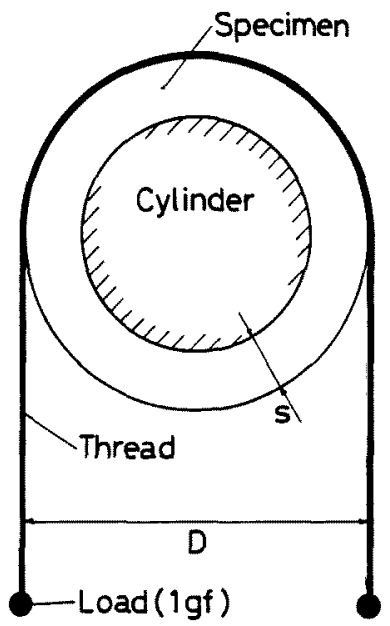

Fig. 2 Method to measure the diameter of a cylinder covered with a fabric.

The procedure to estimate the heat transfer coefficient is described in detail at Section 3.

\subsection{Experimental conditions}

The main flow velocities used are $0.5,1.0,1.8$, 3.3 and $6.0 \mathrm{~m} / \mathrm{s}$. The surface temperature of the cylinder was chosen in the range from 60 to $70^{\circ} \mathrm{C}$. The physical properties of the fabric samples are shown in Table 1 .

\section{Determination of heat transfer coefficient}

We here present how to determine the heat transfer coefficient from the temperature profile in the fabric.

\subsection{Determination of temperature profile inside fabric specimen}

We suppose that a cylindrical heat source is covered with a fabric and set in a uniform air velocity field (see Fig. 3). In a steady state, the temperature field, $u$, inside the specimen is described by

$$
\frac{\partial^{2} u}{\partial^{2}}+\frac{1}{r} \cdot \frac{\partial u}{\partial r}+\frac{1}{r^{2}} \cdot \frac{\partial^{2} u}{\partial \phi^{2}}=0,
$$

where $(r, \phi)$ is the two-dimensional polar coordinates with the origin sited on the axis of the cylinder.

The boundary conditions are chosen as

$$
\begin{aligned}
& u=u_{0} \text { (const.) at } r=R_{0}, \\
& u=u_{\mathrm{s}}(\phi), \text { at } r=R_{0}+s,
\end{aligned}
$$

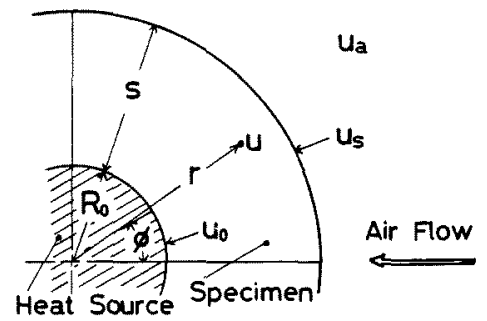

Fig. 3 Illustration of the polar coordinate to describe the temperature field in the

\begin{tabular}{|c|c|c|c|c|c|c|}
\hline \multirow[t]{2}{*}{ Description } & \multirow[t]{2}{*}{ Material } & \multirow[t]{2}{*}{ Weave } & \multicolumn{2}{|c|}{$\begin{array}{l}\text { Weave } \\
\text { density }\end{array}$} & \multirow{2}{*}{$\begin{array}{c}\text { Thickness } \\
\mathrm{cm}\end{array}$} & \multirow{2}{*}{$\begin{array}{l}\text { Bulk } \\
\text { density } \\
\mathrm{g}^{\mathrm{f} / \mathrm{cm}^{2}}\end{array}$} \\
\hline & & & Ends/cm & Picks/cm & & \\
\hline Nylon sheet & Nylon & - & - & - & 0.022 & 0.029 \\
\hline Tweed & $\begin{array}{l}\text { Wool; } 70 \%, \\
\text { Polyester; } 10 \% \text {, } \\
\text { Nylon; } 10 \% \text {, } \\
\text { Acrylic; } 10 \%\end{array}$ & $2 / 2$ twill & 13 & 12 & 0.113 & 0.027 \\
\hline Denim & Cotton & $3 / 1$ twill & 18 & 26 & 0.076 & 0.032 \\
\hline Knitted fabric & $\begin{array}{l}\text { Acrylic; } 70 \% \text {, } \\
\text { Wool; } 30 \%\end{array}$ & - & $\begin{array}{c}7 \\
\text { (wale } / \mathrm{cm} \text { ) }\end{array}$ & $\begin{array}{c}6 \\
\text { (cource } / \mathrm{cm} \text { ) }\end{array}$ & 0.149 & 0.030 \\
\hline
\end{tabular}
specimen.

Table 1 Sample description. 
and

$\partial u / \partial \phi=0$ for $\phi=0, \pi, R_{0}<r<R_{0}+s$,

where $R_{0}$ is the radius of the cylinder, $s$ is the thickness of the specimen, and $u_{0}$ and $u_{\mathrm{s}}$ are the temperatures of the specimen at $r=R_{0}$ and at $r=R_{0}+s$.

It is difficult to solve Eq. (1) theoretically under the boundary conditions (2), so we will try to determine the temperature field numerically using a finite difference method.

We assume that the temperature field is symmetric with respect to the center line of the tunnel and the specimen is homogeneous and isotropic.

In terms of $R_{0}$ and the air temperature at infinity $u_{a}$, we introduce the following dimensionless variables,

$$
T=\frac{u-u_{\mathrm{a}}}{u_{0}-u_{\mathrm{a}}} \quad \text { and } \quad R=\frac{r}{R_{0}}
$$

Then, Eqs. (1), (2) 1 and $(2)_{2}$ are reduced to the dimensionless expressions as follows:

$$
\begin{aligned}
& \frac{\partial^{2} T}{\partial R^{2}}+\frac{1}{R} \cdot \frac{\partial T}{\partial R}+\frac{1}{R^{2}} \cdot \frac{\partial^{2} T}{\partial \phi^{2}}=0, \\
& T=1 \quad \text { at } R=1,
\end{aligned}
$$

and

$$
T=\frac{u_{\mathrm{s}}-u_{\mathrm{a}}}{u_{0}-u_{\mathrm{a}}} \quad \text { at } \quad R=1+\frac{s}{R_{0}}
$$

The reduced temperature field is shown in Fig. 4. The finite difference approximation transforms Eqs, (4) and (5) into

$$
T_{i, j}=\frac{\frac{T_{i+1, j}+T_{i-1, j}}{(\Delta R)^{2}}+\frac{1}{R_{i}} \cdot \frac{T_{i+1, j}}{\Delta R}+\frac{1}{R_{i}^{2}} \cdot \frac{T_{i, j+1}+T_{i, j-1}}{(\Delta \phi)^{2}}}{\frac{2}{(\Delta R)^{2}}+\frac{1}{R_{i} \Delta R}+\frac{2}{R_{i}^{2}(\Delta \phi)^{2}}},
$$

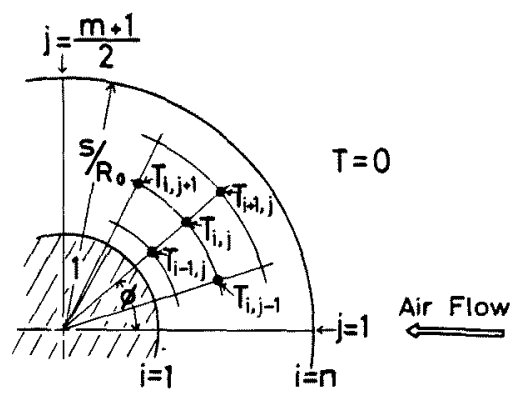

Fig. 4 Illustration of the network on which the temperature profile is evaluated.

$$
T_{1, j}=1
$$

and

$$
T_{n, j}=\frac{u_{n, j}-u_{\mathrm{a}}}{u_{0}-u_{\mathrm{a}}}
$$

where $\Delta R=\left(s / R_{0}\right) /(n-1), \quad \Delta \phi=\pi(m-1)$ and $R_{l}=$ $1+\Delta R(i-1)$, and in addition the following approximation is assumed,

$$
\left[\frac{\partial T}{\partial R}\right]_{R=1+s / R_{0}} \simeq \frac{T_{n, j}-T_{n-1, j}}{\Delta R}
$$

The following relations are deduced from the boundary condition $(2)_{3}$, because the points $(i, 0)$ and $(i, m+1)$ are the mirror images of the points $(i, 2)$ and $(i, m-1)$ :

$$
T_{i, 0}=T_{i, 2} \quad \text { and } \quad T_{i, m+1}=T_{i, m-1}
$$

As Eq. (6) is a simultaneous algebraic linear equation with respect to $T_{i, j}$, it can be solved under the boundary conditions (7), and the approximate solutions of Eq. (4) are obtained.

\subsection{Determination of thermal conductivity of fabric $\lambda$}

If the thermal conductivity, $\lambda$, of the fabric is known, the heat transfer coefficient can be obtained from the heat balance relation at the surface of the specimen. Assuming that the heat quantity, $Q$, generated per unit time in the cylinder is liberated from the lateral surface of the clothed cylinder, the following relation holds,

$$
\begin{aligned}
Q & =\int_{A}-\lambda\left[\frac{\partial u}{\partial r}\right]_{r=R_{0}+s} d A \\
& =-\lambda_{l}\left(R_{0}+s\right) \int_{0}^{2 \pi}\left[\frac{\partial u}{\partial r}\right]_{r=R_{0}+s} d \phi \\
& =-\lambda_{l}\left(u_{0}-u_{\mathrm{a}}\right)\left(1+s / R_{0}\right) \int_{0}^{2 \pi}\left[\frac{\partial T}{\partial R}\right]_{R=1+s / R_{0}} d \phi
\end{aligned}
$$

where $l$ is the length of the heated part of the cylinder. Thus, we have

$$
\begin{aligned}
Q & =-\lambda_{l}\left(u_{0}-u_{\mathbf{a}}\right)\left(1+s / R_{0}\right) \frac{\pi}{m-1} \\
& \times\left[\frac{T_{n, 1}-T_{n-1,1}}{\Delta R}+\frac{T_{n, m}-T_{n-1, m}}{\Delta R}+2 \sum_{j=2}^{m-1} \frac{T_{n, j}-T_{n-1, j}}{\Delta R}\right] .
\end{aligned}
$$


Substituting $T_{i, j}$ calculated from Eq. (6) and the heat quantity $Q$ into Eq. (9), the thermal conductivity $\lambda$ can be determined.

\subsection{Determination of heat transfer coefficient $h_{\mathrm{c}}$}

Heat balance at the specimen surface leads to the relation

$$
-\lambda\left[\frac{\partial u}{\partial r}\right]_{r=R_{0}+s}=h_{\mathrm{c}+\mathrm{r}}\left(u_{\mathrm{s}}-u_{\mathrm{a}}\right),
$$

where $h_{c+r}$ is the local heat transfer coefficient which reflects the effects both of convection and radiation, and

$$
h_{\mathrm{c}+\mathrm{r}}=h_{\mathrm{c}}+h_{\mathrm{r}} \text {, }
$$

$h_{\mathrm{c}}$ being the local heat transfer coefficient for convection; $h_{\mathrm{r}}$ being that for radiation. The latter is calculated from the following approximate equation at room temperature,

$$
h_{\mathrm{r}} \simeq \frac{4}{100} \varepsilon C_{0}\left[\frac{u_{m}}{100}\right]^{3},
$$

where the emissivity of the fabric $\varepsilon=0.90$, the radiant coefficient of a black body $C_{0}=4.88(\mathrm{kcal} /$ $\left.\mathrm{m}^{2}, \mathrm{~h}, \mathrm{~K}^{4}\right)$, and the film temperature $u_{m}=273.15+$ $\left(u_{\mathrm{s}}+u_{\mathrm{a}}\right) / 2(\mathrm{~K})$ were used. Then, $h_{\mathrm{c}}$ is determined from Eqs. (11), (12), and the following normalized equation (13),

$$
h_{\mathrm{c}+\mathrm{r}}=\frac{\lambda}{R_{0} \Delta R}\left[\frac{T_{n-1, j}}{T_{n, j}}-1\right]
$$

The local Nusselt number $N u$ is defined by

$$
N u=\frac{2 h_{\mathrm{c}}\left(R_{0}+s\right)}{\lambda_{\mathrm{a}}} \text {. }
$$

where $\lambda_{\mathrm{a}}$ is the thermal conductivity of air at the film temperature. The mean heat transfer coefficient $\bar{h}_{\mathrm{c}}$ and the mean Nusselt number $\overline{N u}$ are expressed as follows:

$$
\bar{h}_{\mathrm{c}}=\frac{1}{2 \pi} \int_{0}^{2 \pi} h_{\mathrm{c}} d \phi \simeq \frac{1}{2(m-1)}\left[h_{\mathrm{c}, \mathrm{i}}+h_{\mathrm{c}, m}+2 \sum_{j=2}^{m-1} h_{\mathrm{c}, j}\right],
$$

$$
\overline{N u}=\frac{1}{2 \pi} \int_{0}^{2 \pi} N u d \phi \simeq \frac{1}{2(m-1)}\left[N u_{1}+N u_{m}+2 \sum_{j=2}^{m-1} N u_{j}\right] .
$$

\section{Surface temperature of specimen}

In general, it is very difficult to measure the surface temperature of a fabric specimen, because the surface is too uneven and nappy to be welldefined. Therefore, when one refers to the surface temperature, he has to specify how it is detected. In this paper, we define the surface temperature to be the extrapolated value of the internal temperature profile of the specimen.

Figure 5 shows three examples of the internal temperature profile, comparing the surface temperatures estimated by extrapolation with those directly measured by using thermocouples attached on the specimen surface. The differences are within a range of about $\pm 0.3 \mathrm{deg}$. Direct measurement of the surface temperature can not always be carried out reasonably for objects of nappy surface structure, so that we employed the extrapolation method as a more confidential one.

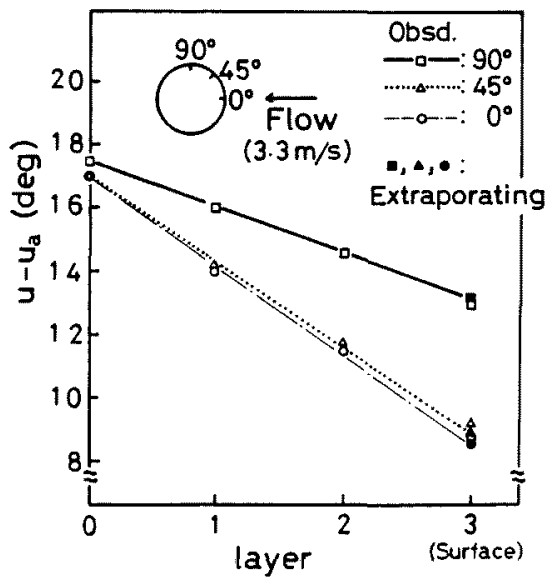

Fig. 5 An example of the temperature profile and the comparison of surface temperatures obtained by extrapolation from those measured with thermocouples attached on the surface of the specimen.

\section{Correction of internal temperature}

As described in section 3, the surface temperature of the specimen is used in order to estimate local heat transfer coefficient. Therefore if the internal temperature profile fluctuates, the values of the surface temperatures and, hence, the values of local heat transfer coefficients may vary considerably to lower the degree of confidence in our 


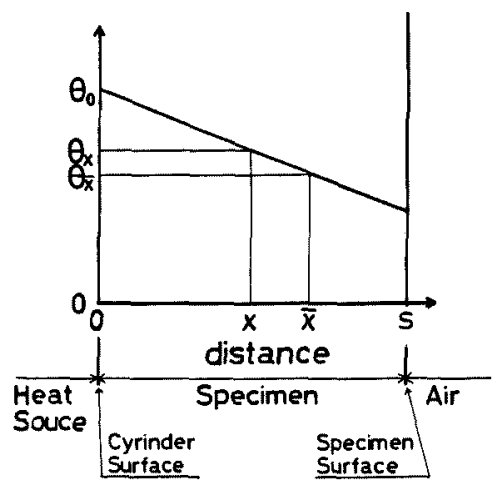

Fig. 6 Relation between location of thermocouple and its measured temperature.

estimation. In order to reduce such errors, we adopt the following correction for the temperature profile using informations on the natural convection as follows.

Figure 6 shows the spatial distribution of temperature $\theta_{x}$ for natural convection, where the temperature gradient in the specimen is assumed to be constant. The measured $\theta_{x}$ may be expected to be accompanied by some error because of the uncertainty in the location of the thermocouple. Assuming that the true value of $\theta_{x}$ may be estimated as the average, $\theta_{\bar{x}}$, of measured temperature, the following relation is holds.

$$
q=-\lambda \frac{\theta_{0}-\theta_{x}}{x}=-\lambda \frac{\theta_{0}-\theta_{\bar{x}}}{\bar{x}},
$$

where $q$ is the heat flux. Then,

$$
\frac{\bar{x}}{x}=\frac{\theta_{0}-\theta_{\bar{x}}}{\theta_{0}-\theta_{x}}
$$

We call Eq. (18) the correction factor. The errors in $\theta_{x}$ which originated from uncertainty in detecting position must be of the same order both for natural and forced convections. Thus we have an idea to correct the temperature, $u_{x}$, for forced convection, using the correction factor as follows:

$$
u_{x}^{*}=u_{0}-\frac{\theta_{0}-\theta_{\bar{x}}}{\theta_{0}-\theta_{x}}\left(u_{0}-u_{x}\right)
$$

For a two-ply tweed fabric as an example, the correction factor was estimated through temperature measurement at various locations of thermocouples, as shown in Fig. 7. This figure shows that the fluctuation in the location is within the region

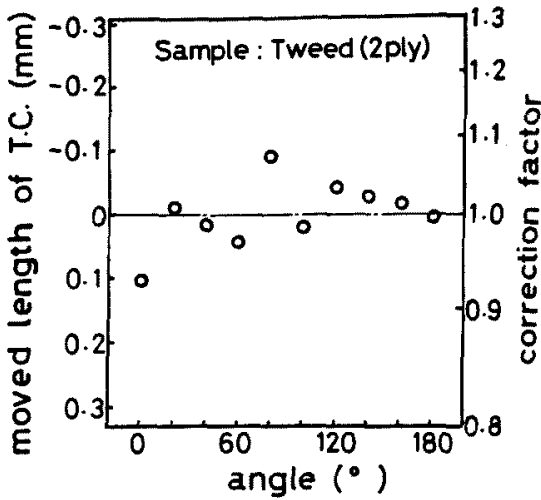

Fig. 7 An example of moved length of thermocouple from given location and correction factor.

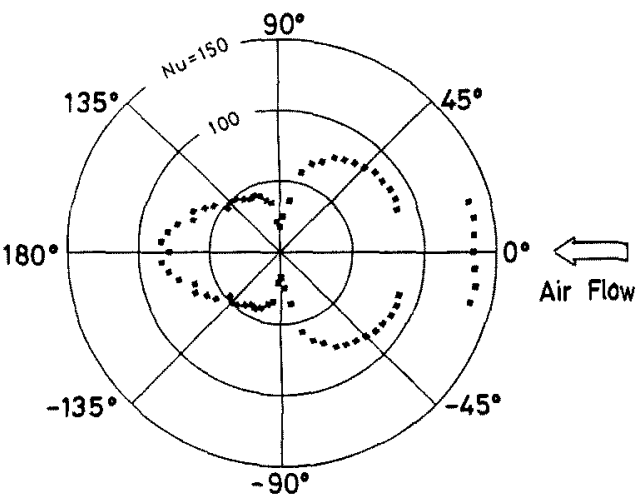

Fig. 8 An example for the distribution of local Nusselt number uncorrected. The sample is a tweed of 2 ply and the corrected Reynolds number $R e^{*}$ is 16200 .

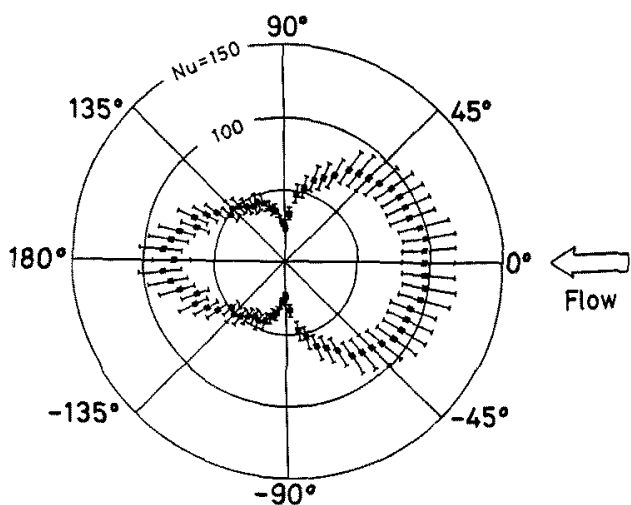

Fig. 9 Corrected distribution of local Nusselt number corresponding to the same case as in Fig. 8, the error bars taking account of fluctuations in air temperature, thickness of specimen and estimated temperature of specimen surface. 
of $\pm 0.1 \mathrm{~mm}$. But it was found that even such order of fluctuation affects considerably the above correction. The local Nusselt number obtained in the experiments for the same sample is shown in Fig. 8 without correction and in Fig. 9 with correction. The error bars in Fig. 9 take account of the fluctuations in the air temperature, in the specimen thickness, and in the estimated surface temperature. Figure 8 shows that the local Nusselt number is discontinuous especially at the position of $\phi= \pm 20^{\circ}$ where the temperature is measured with different thermocouples, while the corrected results in Fig. 9 vary continuously at the angle. This suggests that the above correction was successful.

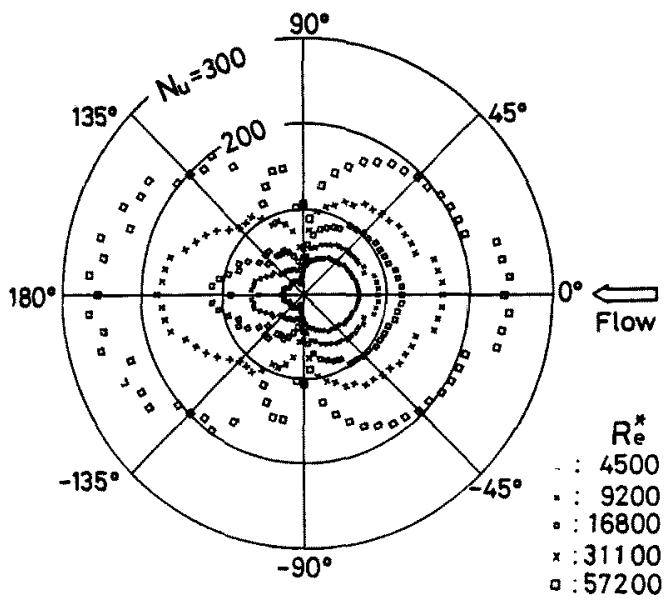

Fig. 10 Distribution of $\mathrm{Nu}$ for different values of $R e^{*}$ (nylon sheet of $12 \mathrm{ply}$ ).

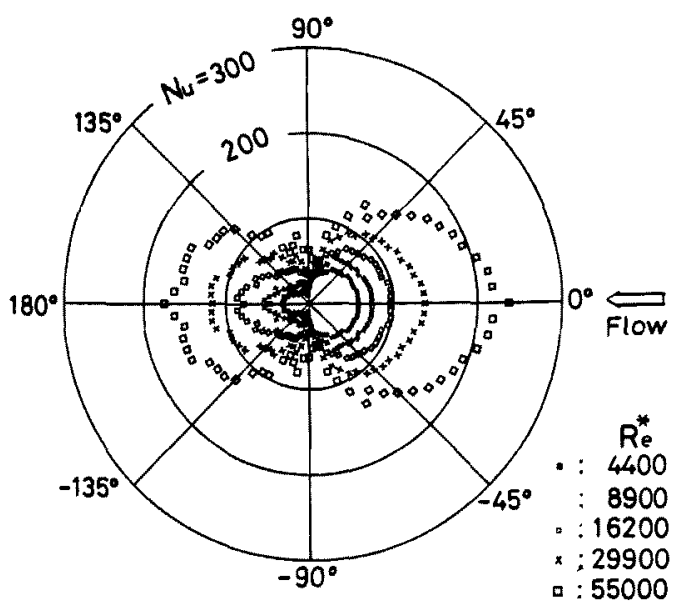

Fig. 11 Distribution of $\mathrm{Nu}$ for different values of $R e^{*}$ (tweed of 2 ply).

\section{Correction of main flow velocity}

It is necessary to correct the error caused by the solid blockage effect in the main flow velocity. This effect and its correction were described in a previous paper ${ }^{1)}$.

\section{Results and discussions}

\subsection{Local Nusselt number $\mathrm{Nu}$}

In Figs. $10 \sim 13$, the distribution of $N u$, i.e. the local heat transfer coefficient $h_{c}$ for corrected Raynolds number $R e^{*}$, is shown without error bar for each fabric sample. These figures show that $N u$ becomes maximum at the frontal point $(\phi=0)$, decreases slowly along the circumference of the

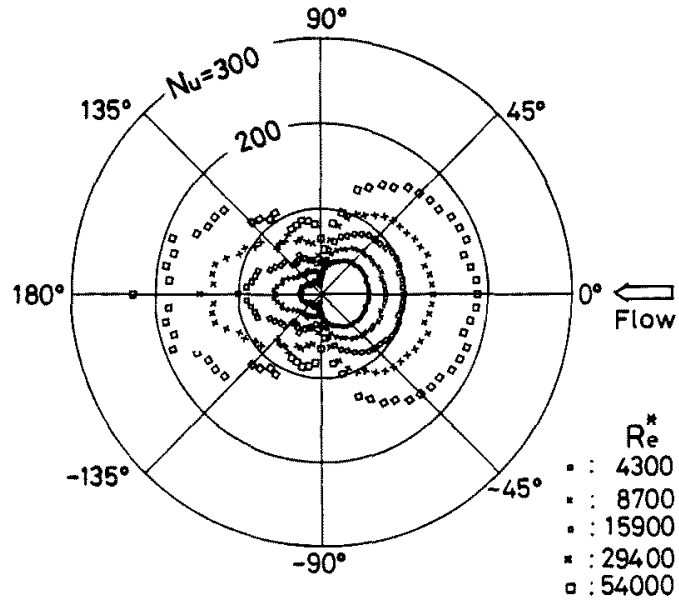

Fig. 12 Distribution of $\mathrm{Nu}$ for different values of $R e^{*}$ (denim of 4 ply).

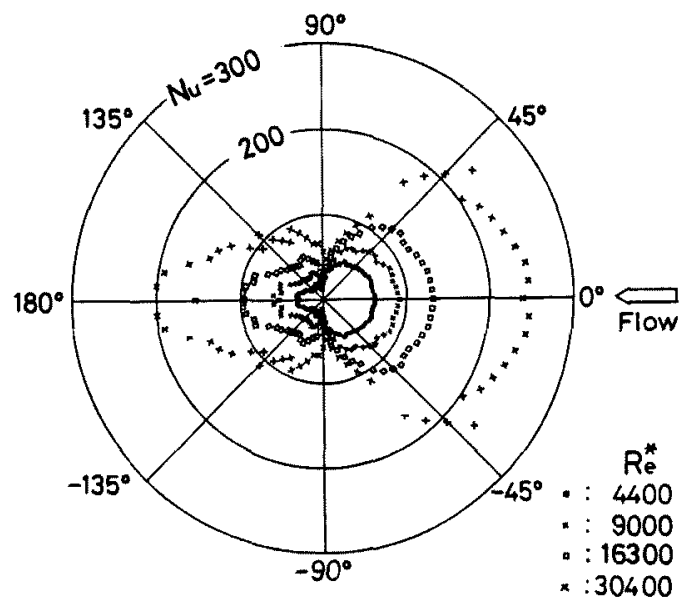

Fig. 13 Distribution of $N u$ for different values of $\operatorname{Re}^{*}$ (knitted fabric of 2 ply). 
Table 2 Location where local heat transfer coefficient becomes minimum.

unit: degree

\begin{tabular}{|l|c|c|c|c|c|}
\hline \multirow{2}{*}{ Sample } & \multicolumn{5}{|c|}{ Wind velocity $(\mathrm{m} / \mathrm{s})$} \\
\cline { 2 - 6 } & $\frac{0.5}{4500}$ & $\frac{1.0}{9200}$ & $\frac{1.8}{16700}$ & $\frac{3.3}{31000}$ & $\frac{6.0}{57000}$ \\
\hline Nylon sheet & 100 & 100 & 95 & 90 & 85 \\
\hline Tweed & 100 & 95 & 90 & 85 & 80 \\
\hline Denim & 100 & 95 & 90 & 90 & 85 \\
\hline Knitted fabric & 100 & 95 & 90 & 85 & - \\
\hline
\end{tabular}

cylinder until about $\phi= \pm 85^{\circ}$, becomes minimum suddenly at about $\phi= \pm 90^{\circ}$, and increases gradually until $\phi=180^{\circ}$, regardless of the kind of samples and $\operatorname{Re}^{r} \quad$ It is also clear that $N u$ increases with increase in $R e^{\prime}$ over the full region and the increasing rate is smaller at the frontal region than at the rear. The distribution of $N u$ agrees qualitatively well with those in literatures ${ }^{4,5)}$. In Table 2, the point at which $N u$ becomes minimum is shown for each sample and $R e^{*}$ From the table it is evident that the minimum point moves toward the front of the cylinder with increase in $R e^{*}$

\subsection{Mean Nusselt number $\overline{N u}$}

In Fig. 14, $\overline{N u}$, which is the mean heat transfer coefficient of each sample, is plotted against $R e^{*}$ The solid line denotes the empirical formula proposed by Douglas and Churchill ${ }^{6}$ for forced convection. Fig. 14 shows that $\overline{N u}$ agrees very well to the solid line for the nylon sheet. From

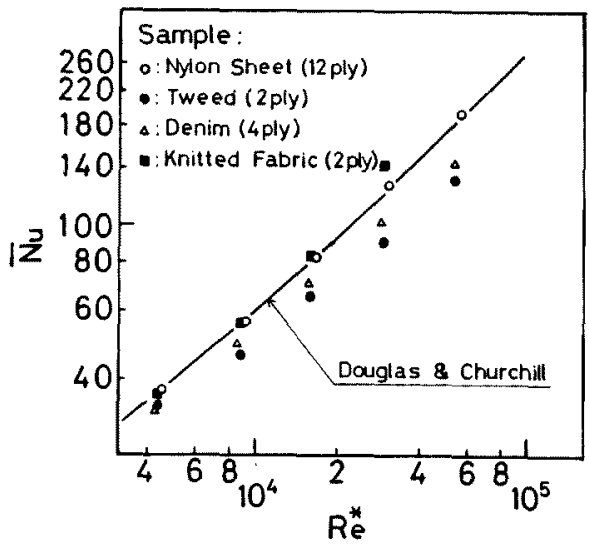

Fig. 14 Mean Nusselt number $\overline{N u}$ against the corrected Reynolds number $R e^{*}$ for different samples. this it seems reasonable to assume that $\overline{N u}$ for the sheet-like sample is equivalent to that of a cylinder which has a smooth surface. However, $\overline{N u}$ for fabrics does not necessarily agree with the solid line. This fact suggests that fabrics with rough surfaces are essentially different in $\overline{N u}$ from those with smooth surfaces.

\subsection{Visualization of flow around cylinder}

From the distribution of $\mathrm{Nu}$ and the fact that increase in air velocity (hence, in $R e^{*}$ ) shifts forwards to the point where $N u$ gets its minimum, the flow field may be supposed to be as follows: the boundary layer around the cylinder developes gradually from the stagnation point $(\phi=0)$ until a point $\phi$ near $90^{\circ}$ where $N u$ becomes minimum and separation of flow occurs, and then, beyond this separating point, the flow becomes turbulent. The discrepancy in $\overline{N u}$, between a smooth surface and a rough surface, may be considered to arise from the difference in the thickness of boundary layer which reflects the difference in surface textures. In order to check up on this supposition we carried out the experiments to visualize the flow around a cylinder using a smoke wind tunnel. An acrylic cylinder $100 \mathrm{~mm}$ in diameter was set horizontally in the tunnel, and the flow around the cylinder was visualized. The typical results obtained are shown in Figs. $15 \mathrm{~A}$ and $15 \mathrm{~B}$, where the flow velocity is 6.0 and $12.0 \mathrm{~m} / \mathrm{s}$, respectively. The other samples showed also similar behaviours. From Fig. 15, it is found that the flow separation arises at an angle $\phi$ near $90^{\circ}$, the flow is turbulent beyond this point, and the difference in the flow patterns is not clear.

A further study with more precise experiments is necessary to reveal the correlation between the flow pattern and the heat transfer coefficient.

\subsection{Rest air film on surface of cylinder}

For the cylinder covered with the tweed or denim fabrics, $\overline{N u}$ is smaller than that for the naked cylinder, as shown in Fig. 14. This is supposed to be due to the difference in surface texture. Fabrics such as tweed or denim, in general, are too hard to be passed by air because of their extremely dense texture. When a cylinder which is covered with such a fabric is placed in an air flow, air passes by the fabric surface but does not penetrate into or flow through the pores in the fabric: in other words, air near the surface remains 

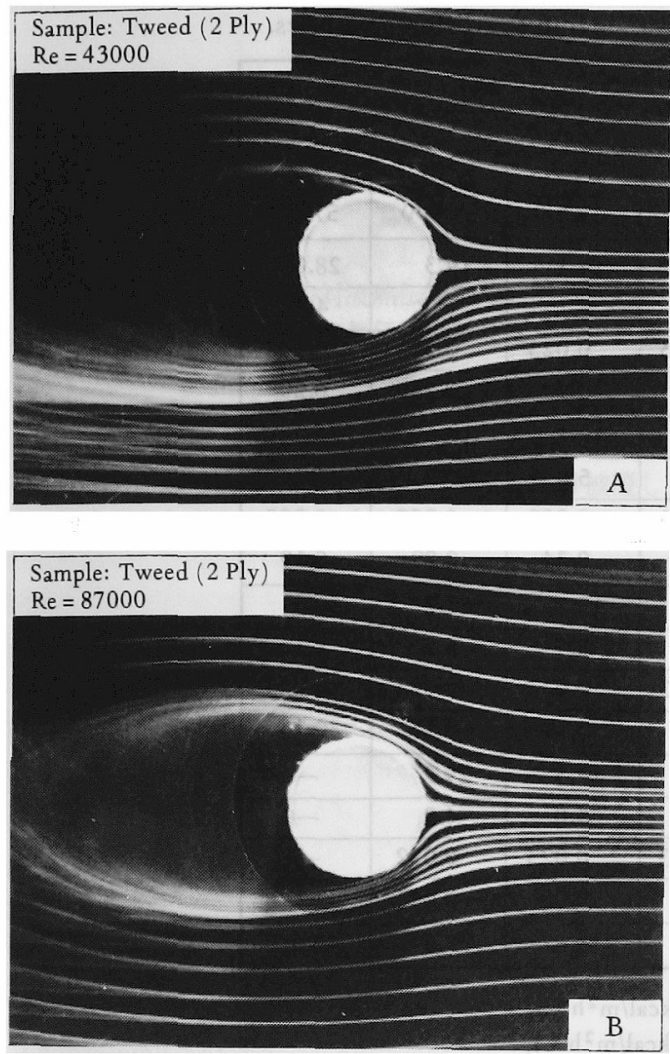

Fig. 15 Visualization of the air flow around a clothed cylinder (tweed of 2 ply).
A) $R e$ is 43000 . B) $R e$ is 87000 .

staying still. Therefore we can treat approximately the inactive part of air as a rest air layer, and determine the thickness of this hypothetical air film $\delta_{\mathrm{a}}$.

The following relation holds approximately,

$$
\begin{aligned}
Q & =2 \pi\left(R_{0}+s\right)\left(\bar{h}_{\mathrm{c}}+\bar{h}_{\mathrm{r}}\right)\left(\bar{u}_{\mathrm{s}}-u_{\mathrm{a}}\right) \\
& =2 \pi\left(R_{0}+s+\delta_{\mathrm{a}}\right)\left(\bar{H}_{\mathrm{c}}+\bar{H}_{\mathrm{r}}\right)\left(\bar{u}_{\mathrm{s}}^{\prime}-u_{\mathrm{a}}\right),
\end{aligned}
$$

and

$$
Q=\frac{2 \pi \lambda_{\mathrm{a}}\left(\bar{u}_{\mathrm{s}}^{\prime}-\bar{u}_{\mathrm{s}}\right)}{\ln \left(1+\delta_{\mathrm{a}} /\left(R_{0}+s\right)\right)} \simeq \frac{2 \pi\left(R_{0}+s\right) \lambda_{\mathrm{a}}\left(\bar{u}_{\mathrm{s}}^{\prime}-\bar{u}_{\mathrm{s}}\right)}{\delta_{\mathrm{a}}},
$$

where, $Q$ is the rate of heat flow, $\overline{h_{c}}$ the mean convective heat transfer coefficient obtained from the experiments, $\bar{h}_{\mathrm{r}}$ the mean radiational heat transfer coefficient used at the experiments, $\bar{u}_{\mathrm{s}}$ the mean temperature on the specimen surface, $u_{\mathrm{a}}$ the air temperature at infinity, $\overline{u_{\mathrm{s}}^{\prime}}$ the surface temperature of the rest air film, $\overline{H_{\mathrm{c}}}$ the mean convective heat transfer coefficient recommended by Douglas and Churchill ${ }^{6)}, \overline{H_{\mathrm{r}}}$ the mean radiational heat transfer coefficient on the film surface, and $\lambda_{\mathrm{a}}$ the thermal conductivity of air.

Assuming $\delta_{\mathrm{a}} \ll R_{0}+S$ and $\overline{H_{\mathrm{r}}} \simeq \overline{h_{\mathrm{r}}}, \delta_{\mathrm{a}}$ is obtained from Eqs. (20) and (21) as follows:

$$
\delta_{\mathrm{a}}=\lambda_{\mathrm{a}}\left\{\left(\bar{h}_{\mathrm{c}}+\bar{h}_{\mathrm{r}}\right)^{-1}-\left(\bar{H}_{\mathrm{c}}+\bar{h}_{\mathrm{r}}\right)^{-1}\right\}
$$

The values used for $h_{\mathrm{c}}, h_{\mathrm{r}}, \lambda_{\mathrm{a}}$ and $H_{\mathrm{c}}$, and the calculated values of $\delta_{\mathrm{a}}$ are shown in Table 3 . The average thickness of the rest air film is about $0.25 \mathrm{~mm}$ for the tweed and $0.16 \mathrm{~mm}$ for the denim. These values seem reasonable because the specimen surface are considered to be comparatively smooth.

On the other hand, the mean heat transfer coefficient $\overline{N u}$ is larger for the knitted fabric than for the fabrics having more smooth surfaces. It seems to be the reason that air flows easily through the fabric because of the coarse texture; the air flow results directly the decrease in the internal temperature of the fabric and the increase in the apparent heat transfer coefficient. This can be explained by comparing Fig. 13 and Figs. 11 12 as follows; these figures show that $N u$ of knitted fabric is larger than those of denim and tweed if $R e^{*}$ 's of them have similar value in the frontal region of the cylinder. This phenomenon was reported also by Takeuchi et al. ${ }^{3)}$. However, in this study, we assumed that the temperature gradient was constant in the specimen to estimate its surface temperature, so that this analysis is not applicable to the case that the air flow through the fabric can not be neglected.

\section{Conclusions}

From the experiments and analysis on the forced-convection heat transfer from the outer surface of a clothed cylinder, the following results were obtained:

1. The experimental and analytical methods used in this study are applicable to the problem of heat transfer from the surface of fabrics less permeable to air such as tweed and denim.

2. For less permeable fabrics, the heat transfer coefficient of a clothed cylinder is smaller than that of the naked cylinder, and it is possible to treat the fabrics as if they have a smooth surface 
Table 3 Estimated thickness of rest air film for different fabrics.

\begin{tabular}{|c|c|c|c|c|c|c|}
\hline \multirow{3}{*}{ Sample } & & \multicolumn{5}{|c|}{ Wind velocity $(\mathrm{m} / \mathrm{s})$} \\
\hline & & \multicolumn{5}{|c|}{$R e^{*}$} \\
\hline & & $\frac{0.5}{4500}$ & $\frac{1.0}{9200}$ & $\frac{1.8}{16700}$ & $\frac{3.3}{31000}$ & $\frac{6.0}{57000}$ \\
\hline \multirow{4}{*}{ Tweed ( 2 ply) } & $h_{\mathrm{c}}$ & 7.4 & 10.0 & 14.1 & 19.3 & 28.0 \\
\hline & $h_{I}$ & 5.2 & 5.1 & 5.1 & 5.0 & 4.9 \\
\hline & $\lambda_{\mathrm{g}}$ & 0.023 & 0.023 & 0.023 & 0.023 & 0.022 \\
\hline & $\delta_{\mathrm{a}}$ & 0.13 & 0.25 & 0.23 & 0.25 & 0.20 \\
\hline \multirow{4}{*}{ Tweed ( 3 ply) } & $h_{c}$ & 6.6 & 9.7 & 12.5 & 18.0 & 28.3 \\
\hline & $h_{\mathrm{r}}$ & 5.2 & 5.1 & 5.0 & 4.9 & 4.9 \\
\hline & $\lambda_{3}$ & 0.023 & 0.023 & 0.023 & 0.022 & 0.022 \\
\hline & $d_{a}$ & 0.26 & 0.28 & 0.34 & 0.29 & 0.19 \\
\hline \multirow{4}{*}{ Denim (4 ply) } & $h_{\mathrm{c}}$ & 7.2 & 10.8 & 15.2 & 21.7 & 30.6 \\
\hline & $h_{\mathrm{r}}$ & 5.4 & 5.3 & 5.3 & 5.2 & 5.1 \\
\hline & $\lambda_{a}$ & 0.023 & 0.023 & 0.023 & 0.023 & 0.023 \\
\hline & $\delta_{\mathrm{a}}$ & 0.16 & 0.16 & 0.16 & 0.16 & 0.16 \\
\hline \multirow{5}{*}{$\begin{array}{l}\text { Knitted fabric } \\
\text { ( } 2 \text { ply) }\end{array}$} & $h_{\mathrm{c}}$ & 7.8 & 11.8 & 17.5 & 29.9 & 一 \\
\hline & $h_{\mathrm{r}}$ & 5.2 & 5.1 & 5.0 & 4.9 & - \\
\hline & $\lambda_{\mathrm{a}}$ & 0.023 & 0.023 & 0.023 & 0.022 & 二 \\
\hline & $s_{3}$ & 0.08 & 0.08 & 0.05 & -0.04 & - \\
\hline & $H_{\mathrm{c}}$ & 8.4 & 12.9 & 18.6 & 27.8 & 42.0 \\
\hline
\end{tabular}

$h_{c} ;$ convective heat transfer coefficient $\left(\mathrm{kcal} / \mathrm{m}^{2} \mathrm{~h}^{\circ} \mathrm{C}\right)$,

$h_{\mathrm{r}} ;$ radiational heat transfer coefficient $\left(\mathrm{kcal} / \mathrm{m}^{2} \mathrm{~h}^{\circ} \mathrm{C}\right)$,

$\lambda_{\mathrm{a}}$; thermal conductivity of air $\left(\mathrm{kcal} / \mathrm{mh}^{\circ} \mathrm{C}\right)$,

$\delta_{\mathrm{a}}$; estimated thickness of rest air film calculated from Eq. (22) (mm),

$H_{c}$; convective heat transfer coefficient recommended by Douglas and Churchill ${ }^{6}$ )

$\left(\mathrm{kcal} / \mathrm{m}^{2} \mathrm{~h}^{\circ} \mathrm{C}\right)$.

by assuming a rest air film on the specimen surface. 3. For permeable fabrics such as knitted fabrics, the apparent heat transfer coefficient is larger than that for a smooth surface. Therefore, the present analytical method must be improved.

\section{Reference}

1) Y. Kamata, T. Kato, H. Azumi and S. Watanabe, Sen-i Gakkaishi, 42, T-155 (1986)

2) M. Takeuchi, N. Issiki and Y. Ishibashi, JSME,
48, 425, p. 97 (1982)

3) M. Takeuchi, Y. Ishibashi, A. Nagasaka and N. Issiki, JSME, 48, 436, p. 2518 (1982)

4) M. Mikheyev, "Fundamentals of Heat Transfer", Peace Publishers, Japanese Translation by $\mathrm{H}$. Uchida and S. Kamata, Tokyo Tosyo, Tokyo, pp. 85-86 (1966)

5) Y. Katto, "Dennetsu Gairon", Yokendo, Tokyo, p.154 (1964)

6) W. J.M. Douglas and S. W. Churchill, Chem. Eng. Progr. Symp. Series, 52, 23 (1956) 


\section{人体加らの対流熱伝達}

（第 2 報 熱伝達に及ばす布の影響）

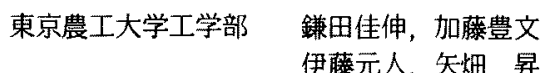

布で被覆した円筒からの対流熱伝達について夷験的に 調べ，その実験結果を用いて熱伝達率に及代す布の影響 について検討した。

ッイードやデニムのような通気性の悪い布の表面から の熱伝達们関して，本報で用いた実験的，解析的方法は 有用であり，布で被䧗した円筒からの熱伝達率は被輹し ない場合よりあ小さくなるととが分かった。そして，て
の場合に対しては，布の表面に静止空気層の存在を仮定 すれば，あたかむ布か滑らかな表面を有する場合の熱伝 達問題として扱うことができることす分かった。編地の ような通気性の良い布に対しては見かけの熱伝達は通気 性の悪い場合よりもかなり大きくなり，乙の場合には本 報の解析法の改良が必要である。 